\title{
Changes of Functional Recovery of Ankle Joint with Application of Rehabilitation Exercise Program after Arthroscopic Modified Brostrom Operation: A Pilot Study
}

\author{
Ji Myeong Park ${ }^{1 *}$, Ho Jin Kim', Se Hee Kong ${ }^{1}$ \\ ${ }^{1}$ Daechan Hospital Sports Medical Research Center, Korea
}

\author{
Received: March 29, 2021 \\ Accepted: April 26, 2021 \\ Published online: April 30, 2021 \\ Keywords: \\ American Orthopaedic Foot and \\ Ankle Society ankle-hind foot \\ Arthroscopic Modified Brostrom \\ Operation \\ Dynamic Stability \\ Isokinetic Muscle Strength \\ Rehabilitation Exercise Program
}

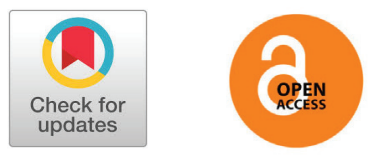

\begin{abstract}
OBJECTIVES The purpose of this study was to demonstrate its effectiveness by applying a systematic rehabilitation exercise program to patients after arthroscopic modified Brostrom operation.

METHODS The research subjects were 13 patients who had arthroscopic modified Brostrom operation, the 60-minute rehabilitation exercise program was applied twice a week for six weeks, and then, subjective evaluation of ankle joint, and its dynamic stability and isokinetic muscle strength were measured.

RESULTS After application of the rehabilitation exercise program, subjective evaluation of the ankle joint $(p<.001)$, its dynamic stability $(p<.001)$ and strengths of the involved side for isokinetic muscle strength peak torque inversion $(p<.001)$, eversion $(p<.01)$, total work inversion $(p<.001)$, eversion $(p<.01)$ uninvolved side peak torque inversion $(p<.001)$, eversion $(p<.01)$, total work $(p<.01)$, muscle endurance of the involved side peak torque inversion $(p<.001)$, eversion $(p<.01)$, total work inversion $(p<.001)$, eversion $(p<.01)$, uninvolved side peak torque inversion $(p<.01)$, total work inversion $(p<.01)$ were significantly increased.

CONCLUSIONS It was confirmed that application of rehabilitation exercise program after arthroscopic modified Brostrom operation was effective for positive possibilities of its settlement as regular rehabilitation exercise program.
\end{abstract}

(c) The Asian Society of Kinesiology and the Korean Academy of Kinesiology
서론

여가활동과 스포츠 활동 인구가 증가하면서 발목 염 좌(ankle sprain)는 스포츠 손상 중 가장 흔한 손상의 하 나가 되었으며, 전 연령의 분포는 활동력이 왕성한 청소 년과 청년층에서 가장 많이 나타났다[1]. 또한, 발목관 절 염좌에서 $85 \%$ 이상이 외측인대 손상으로 발생하고, 한번 발목관절 손상이 있었던 환자의 약 $80 \%$ 는 재손상 이 나타난다. 그중 10 50\%는 만성 통증이나 반복적인

*Correspondence: Ji Myeong Park, Daechan Hospital Sports Medical Research Center 590 Inju-daero, Namdong-gu, Incheon, Korea; Tel: +82-10-8898-8640; E-mail: pjm1313@hanmail.net
재손상 등의 발목 불안정성이 나타나며 [2,3], 6개월 이 상 기능적 또는 기계적 발목 불안정성이 지속되면 만성 발목불안정성이 된다[4]. 이러한 발목 관련 염좌의 치 료를 위해 수술적 치료와 비수술적 치료를 시행하며 비 수술적 치료 시 $80 \%$ 는 발목 관절에 보조기 착용과 비 골근 강화 운동을 통해 개선되지만, 나머지 $20 \%$ 는 수 술적 치료를 시행해야만 한다[5,6].

기존의 수술적 치료 방법은 발목관절 인대 재건술로 Modified Brostrom Operation(MBO)이다. 이 수술의 방법은 비골건을 보존하고 전거비 인대와 종비 인대를 봉합한 후 신근지대의 근위부를 봉합하여 인대를 강화 
하는 것이다[5]. 그러나 $\mathrm{MBO}$ 의 부작용으로는 광범위한 절개, 관절가동범위, 비복신경 손상이 있고 재수술의 가 능성이 크고, 특히 (내번)동작이 제한되는 단점이 있으 므로 수술 후 발목 관절가동범위의 움직임에 한계가 있 을 수 있다[7]. 최근에는 이러한 단점을 보완하는 관절 경 $\mathrm{MBO}$ 를 시행하고 있다. 관절경 $\mathrm{MBO}$ 는 관절경으로 관절내 최소 절개를 하여 병변을 처치한 뒤 외측에 추 가 절개를 시행하여 외측 발목관절 인대를 해부학적으 로 재건하는 방법으로 만성 발목불안정성 환자에게 이 수술을 시행한 결과, 수술 시간을 단축하고 추가 절개로 인한 통증을 감소시키는 만족스러운 결과를 보였다[7]. 이에 더해, 최소 절개 관절경만을 이용하여 $\mathrm{MBO}$ 를 시 행하면 비골건과 비복신경 손상을 줄여주며 수술 시간 단축 및 수술 반흔을 줄일 수 있으며 수술 후 발목 통증 조절에 유리하다고 알려져 있다[7].

그러나 수술 후 더 빠르고 정상적인 일상생활과 스 포츠 활동으로의 복귀를 위해서는 발목 주변의 근력 강 화와 고유수용성 감각의 회복이 필요하며[8], 근력 회 복 및 증가를 위한 방법으로는 등척성(isometric), 등장 성(isotonic) 및 등속성(isokinetic) 운동이 있다[3]. 더 불어 재활운동프로그램 시 저측굴곡(plantar flexion)이 나 배측굴곡(dorsi flexion)처럼 강한 근육 위주의 트레 이닝보다 좌, 우의 평형 및 균형을 조절하기 위한 내번 (inversion)과 외번(eversion) 동작의 근육 트레이닝이 필요하다[9]. 이를 반영하여 본 연구에서 제시된 재활 운동프로그램은 유연성, 등척성, 등장성기능성, 평형성 운동으로 구성하였고, 근기능 향상에 프로그램의 비중 을 두었다.

최근 본 연구와 같은 수술인 관절경 $\mathrm{MBO}$ 후 재활운 동프로그램을 적용한 선행 연구가 있다. 이 연구는 관절 경 $\mathrm{MBO}$ 후 선수들의 빠른 회복을 위하여 수술 6 주 뒤 걷기, 조깅, 달리기 등을 훈련하도록 하였다. 그 결과 연 구에 참여한 모든 선수들이 평상시보다 빠른 운동 현장 으로의 복귀가 가능하였다[10].

위의 연구 결과로부터 관절경 $\mathrm{MBO}$ 후 재활운동프로 그램이 수술 후 회복을 도울 수 있을 것으로 보이나 근력 운동을 포함한 적절한 재활운동프로그램이 제시된 연구 는 아직 수행되지 않았다. 따라서 본 연구의 목적은 관절 경 $\mathrm{MBO}$ 를 시술한 환자를 대상으로 체계적인 재활운동프 로그램을 적용 및 그 결과를 분석하여 재활운동프로그램 구성의 기반이 되는 기초 연구 자료를 제공하는 것이다.

\section{연구방법}

\section{연구대상}

본 연구는 인천지역에 소재한 D병원에서 2020년 1 월부터 2020년 12월까지 척추관절센터 전문의로부터 만성 발목불안정성 진단을 받고, 관절경 $\mathrm{MBO}$ 를 시행 한 환자로 재활운동프로그램에 참여 가능한 13 명을 대 상으로 하였다. 또한 연구의 참여자는 연구의 목적을 이 해하고 자발적인 참여 의사를 밝힌 자이다. 연구 대상자 의 신체적 특성은 <Table 1 >과 같다.

Table 1. Baseline data of study subjects

\begin{tabular}{llll}
\hline & Age (year) & Height $(\mathbf{c m})$ & Weight $(\mathbf{k g})$ \\
\hline $\mathrm{n}=13$ & $26.54 \pm 7.00$ & $169.77 \pm 10.75$ & $66.31 \pm 18.06$ \\
\hline
\end{tabular}

Values are $M \pm S D$.

\section{실험절차 및 설계}

본 연구의 실험 절차는 수술 후 연구 참여자의 관절 에 4 주간 석고 및 공기 부목으로 환부를 고정한 후 2 주 동안 발목 관절가동범위 회복을 위해 유연성 재활운동 프로그램을 적용하였다. 실험 절차는 수술 후 연구 참 여자의 관절에 4 주간 석고 및 공기 부목으로 환부를 고 정한 후, 2 주 동안 발목 관절가동범위 회복을 위해 유 연성 재활운동프로그램을 적용하였다. 그 후(수술 6주 후)에 American Orthopaedic Foot and Ankle Society (AOFAS), 동적 안정성, 등속성 근기능의 차례로 측정 방법에 제시된 설명에 따라 사전 측정을 하였고, 6 주 동 안 재활운동프로그램을 적용 후(수술 12 주 후)에 동일 한 순서와 방법으로 사후 측정을 진행하였다.

\section{재활운동프로그램}

재활운동프로그램은 <Table 2>에 제시한 바와 같 으며, Brotzman et al.가 제시한 재활운동프로그램을 수정·보완하여 적용하였다[11]. 재활운동프로그램 적 용은 수술 후 환부를 고정한 4주 후에 시작되었다. 환 부 고정 직후 4 6주까지는 환측 관절가동범위 확보를 목적으로 유연성 운동프로그램과 동시에 근육의 길이 변화가 일어나지 않으면서 통증 없는 범위로 수행 가능 한 발목 운동인 등척성 운동프로그램을 적용하였다. 수 술 6 8주에는 근육의 길이 변화가 일어나는 등장성 운 동프로그램을 환측 또는 환측과 건측 모두에 적용하였 
Table 2. Rehabilitation exercise program

\begin{tabular}{|c|c|c|c|c|}
\hline & Index & Exercise & Intensity & Side \\
\hline Warm-up & Flexibility & Begin gentle ROM exercises of the ankle (DF, PF, IV, EV) & $\begin{array}{l}\text { 4-6week } \\
(10 \text { sec } \times 10 \text { reps }) \times 3 \text { sets }\end{array}$ & Involved \\
\hline \multirow{5}{*}{$\begin{array}{l}\text { Intensive } \\
\text { muscle } \\
\text { exercise }\end{array}$} & Isometric & Ankle towel isometric exercise (DF, PF, IV, EV) & $\begin{array}{l}\text { 4-6week } \\
(10 \text { sec } \times 10 \text { reps }) \times 3 \text { sets }\end{array}$ & Involved \\
\hline & \multirow{2}{*}{ Isotonic } & $\begin{array}{l}\text { Towel pulling with toe } \\
\text { Ankle tubing exercise (DF, PF, IV, EV) }\end{array}$ & $\begin{array}{l}\text { 6-8week } \\
\text { 10reps } \times 3 \text { sets }\end{array}$ & Involved \\
\hline & & $\begin{array}{l}\text { Toe raise } \\
\text { Calf raise }\end{array}$ & $\begin{array}{l}\text { 6-8week } \\
\text { 10reps } \times 3 \text { sets }\end{array}$ & Both \\
\hline & Functional & $\begin{array}{l}\text { Squat } \\
\text { Lunge } \\
\text { Single step up(Box) } \\
\text { Jump (jump: pain free jump in place) } \\
\text { Hop(hop: one leg jump hop) }\end{array}$ & $\begin{array}{l}\text { 6-12week } \\
\text { 10reps } \times 3 \text { sets }\end{array}$ & Both \\
\hline & Balance & $\begin{array}{l}\text { Single stand hip flex } \\
\text { One leg squat } \\
\text { One leg Y squat }\end{array}$ & $\begin{array}{l}\text { 6-12week } \\
(5 \mathrm{sec} \times 10 \text { reps }) \times 3 \text { sets }\end{array}$ & Both \\
\hline Cool-down & Stretching & & & \\
\hline
\end{tabular}

ROM: Range Of Motion, DF: Dorsi Flexion, PF: Plantar Flexion, IV: Inversion, EV: Eversion

다. 또한 6 12주에는 환측과 건측의 근력 향상과 근기 능을 높이기 위해 기능성, 평형성 운동프로그램도 같이 적용하였다.

재활운동프로그램은 주 2회 총 60 분간 운동전문가 의 지도하에 진행하였다. 단계가 바뀌는 시점에서는 발 목 관절가동범위의 확보와 환자 개인의 상황(통증), 운 동 강도 조절을 확인하였으며, 세트의 중간에 1 2분의 휴식 시간을 제공하였다. 운동 직후 환부에는 얼음을 처 치하여 염증을 예방하였다.

\section{측정항목 및 방법}

\section{American Orthopaedic Foot and Ankle Society (AOFAS) ankle-hind foot}

$\mathrm{AOFAS}$ 는 수술 전과 수술 후 치료의 주관적인 효과 를 평가하기 위한 수집 도구로 의사의 도움 없이 환자 가 발목 관절의 통증, 기능, 정렬을 직접 기재하였다. 이 는 치료 전·후의 주관적인 상태를 수치화하여 객관적으 로 알 수 있는 장점이 있다[12]. 검사 방법은 발목 관절 의 통증 1 문항, 기능 7 문항, 정렬 1 문항 총 9 문항에 해 당하는 질문에 점수를 선택해 점수가 높을수록 발목 관 절의 발목 손상을 입기 전 상태로 돌아가며 총 점수는 100 점 만점으로 하였다.

\section{동적 안정성(Y-Balance test)}

$\mathrm{Y}$-Balance test는 발목 관절의 고유수용성감각과 동적균형능력을 평가하는 검사로서 전방, 후내측, 후외 측의 세가지 방향을 측정하였다[13]. 발목 관절의 동적 안정성은 환측과 건측 모두 측정하며 사전 대비 사후의 증가 여부를 알 수 있고, 양측의 발목 안정성도 비교할 수 있다. 검사 방법은 중앙선에서 대상자의 다리가 전 방, 후내측, 후외측 방향의 선으로 다리를 뻗은 지점까 지의 거리를 $\mathrm{cm}$ 단위로 측정하였으며, 5 번의 연습 후 5 번을 측정하여 제일 잘 나온 값을 사용하였다. 다리 길 이의 차이를 보상하기 위해 표준화 공식을 활용하였고, 그 공식은 다음 <Figure 1 >과 같다.

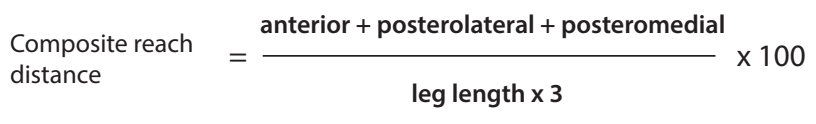

Figure 1. Y-Balance test

\section{등속성 근기능}

등속성 근기능 측정기는 biodex system 4 model(Biodex Medical Systems, Inc., N.Y., USA)를 사용하였다. 측정 항목은 환측과 건측의 근력 근지구력, 근력 및 근지구력의 근비율이다. 발목 기능을 측정하기 위해 측정 전 대상자에게 항목별로 3 회의 예비 연습을 
한 후, 발목 근력을 확인하기 위해 저속도 $60 \% \operatorname{sec~5ㅎㅚ,~}$ 발목 근지구력을 확인하고자 고속도 $120 \% \mathrm{sec} 10$ 회 내 번과 외번을 반복 실시하였다. 각각의 가속도 사이의 휴 식 시간은 30 초로 하고, 발목 관절가동범위는 통증이 없 는 범위 내에서 수행하였다[2]. 측정된 근력값과 근비율 은 biodex에서 자동으로 계산되어 산출되었으며, 근비 율은 환측과 건측의 측정값의 비율(deficit)이다.

\section{자료처리}

본 연구에서는 Window SPSS version 22.0 통계 프로그램을 사용하여 자료를 분석하였다. 실험 처치를 통해 얻은 변인 값을 기술통계분석인 평균(M)과 표준 편차(SD)를 사용하여 산출하였고, 주관적인 변화와 동 적 안정성, 등속성 근기능 전위 정도를 비교하기 위해 서 대응표본 $\mathrm{t}$-검정(Paired $\mathrm{t}$-test)을 하였다. 유의수 준은 $\mathrm{a}=.05$ 이다.

\section{연구결과}

\section{AOFAS의 변화}

AOFAS의 변화는 <Table 3>에 제시한 바와 같으며, 관절경 $\mathrm{MBO}$ 후 재활운동프로그램 적용 전과 비교해서 적용 후 유의하게 증가하였다 $(p<.001)$.

\begin{tabular}{|c|c|c|c|c|c|}
\hline & Pre & Post & $t$ & df & $p$-value \\
\hline$n=13$ & $66.92 \pm 8.38$ & $91.62 \pm 7.02$ & -8.679 & 12 & $.000 * * *$ \\
\hline
\end{tabular}

\section{동적 안정성의 변화}

동적 안정성의 변화는 <Table 4 >에 제시한 바와 같 으며, 관절경 $\mathrm{MBO}$ 후 재활운동프로그램 적용 전과 비 교해서 적용 후 유의하게 증가하였다 $(p<.001)$.

\section{등속성 근기능의 변화}

관절경 $\mathrm{MBO}$ 후 재활운동프로그램을 적용 전과 비 교해서 적용 후에 발목관절 등속성 근기능의 측정 결과 는 다음과 같다.

\section{재활운동프로그램 적용 전 · 후 근력 변화}

등속성 근기능의 근력 $(60 \% \mathrm{sec})$ 변화는 〈Table $5>$ 에 제시한 바와 같다. 환측 peak torque의 내번 $(\mathrm{p}<.001)$ 과 외번 $(\mathrm{p}<.01)$, total work의 내번 $(\mathrm{p}<.001)$ 및 외번 $(\mathrm{p}<.01)$ 은 관절경 $\mathrm{MBO}$ 후 재활운동프로그램 적용 전 과 비교해서 적용 후에 유의하게 증가하였다. 또한 건 측 peak torque의 내번 $(\mathrm{p}<.001)$ 과 외번 $(\mathrm{p}<.01)$, total work의 내번 $(\mathrm{p}<.01)$ 은 관절경 $\mathrm{MBO}$ 후 재활운동프로그 램 적용 전과 비교해서 적용 후에 유의하게 증가하였다.

\section{재활운동프로그램 적용 전·후 근지구력 변화}

등속성 근기능의 근지구력 $(120 \% \mathrm{sec})$ 변화는 <Table 6>에 제시한 바와 같다. 환측의 peak torque

Table 4. Dynamic stability

\begin{tabular}{llllll}
\hline & Pre & Post & t & df & p-value \\
\hline $\mathrm{n}=13$ & $80.98 \pm 8.15$ & $93.28 \pm 5.59$ & -6.763 & 12 & $.000^{* * *}$ \\
\hline \multicolumn{2}{l}{ Values are $\mathrm{M} \pm \mathrm{SD}^{* * * *} p<.001$}
\end{tabular}

\begin{tabular}{|c|c|c|c|c|c|c|c|}
\hline & & & Pre & Post & $\mathbf{t}$ & df & $p$-value \\
\hline \multirow{4}{*}{ Involved } & \multirow{2}{*}{$\begin{array}{l}\text { Peak torque } \\
60^{\circ} / \mathrm{sec}\end{array}$} & Inversion & $13.74 \pm 8.75$ & $24.25 \pm 11.92$ & -4.935 & 12 & $.000^{* * *}$ \\
\hline & & Eversion & $12.38 \pm 5.98$ & $18.51 \pm 7.39$ & -4.064 & 12 & $.002^{* *}$ \\
\hline & \multirow{2}{*}{$\begin{array}{l}\text { Total work } \\
60^{\circ} / \mathrm{sec}\end{array}$} & Inversion & $29.22 \pm 21.31$ & $62.40 \pm 32.05$ & -4.942 & 12 & $.000^{* * *}$ \\
\hline & & Eversion & $29.23 \pm 16.77$ & $50.92 \pm 19.95$ & -4.444 & 12 & $.001^{* *}$ \\
\hline \multirow{4}{*}{ Uninvolved } & \multirow{2}{*}{$\begin{array}{l}\text { Peak torque } \\
60^{\circ} / \mathrm{sec}\end{array}$} & Inversion & $23.52 \pm 7.06$ & $29.20 \pm 7.25$ & -6.046 & 12 & $.000^{* * *}$ \\
\hline & & Eversion & $15.11 \pm 5.46$ & $18.98 \pm 5.64$ & -2.692 & 12 & $.020^{*}$ \\
\hline & \multirow{2}{*}{$\begin{array}{l}\text { Total work } \\
60^{\circ} / \mathrm{sec}\end{array}$} & Inversion & $69.33 \pm 20.59$ & $82.18 \pm 21.15$ & -3.512 & 12 & $.004^{* *}$ \\
\hline & & Eversion & $49.60 \pm 14.68$ & $57.02 \pm 14.70$ & -1.714 & 12 & .112 \\
\hline
\end{tabular}

Values are $\mathrm{M} \pm \mathrm{SD},{ }^{*} p<.05,{ }^{* *} p<.01,{ }^{* * *} p<.001$ 


\begin{tabular}{|c|c|c|c|c|c|c|c|}
\hline & & & Pre & Post & $\mathbf{t}$ & df & $p$-value \\
\hline \multirow{4}{*}{ Involved } & \multirow{2}{*}{$\begin{array}{l}\text { Peak torque } \\
120^{\circ} / \mathrm{sec}\end{array}$} & Inversion & $12.86 \pm 8.22$ & $21.32 \pm 10.80$ & -5.361 & 12 & $.000^{* * *}$ \\
\hline & & Eversion & $10.78 \pm 5.04$ & $14.63 \pm 5.73$ & -3.742 & 12 & $.003^{* *}$ \\
\hline & \multirow{2}{*}{$\begin{array}{l}\text { Total work } \\
120^{\circ} / \mathrm{sec}\end{array}$} & Inversion & $52.07 \pm 41.13$ & $104.33 \pm 59.64$ & -5.343 & 12 & $.000^{* * *}$ \\
\hline & & Eversion & $46.38 \pm 28.85$ & $74.65 \pm 32.83$ & -3.998 & 12 & $.002^{* *}$ \\
\hline \multirow{4}{*}{ Uninvolved } & \multirow{2}{*}{$\begin{array}{l}\text { Peak torque } \\
120 \% \text { sec }\end{array}$} & Inversion & $19.58 \pm 5.45$ & $24.55 \pm 7.73$ & -3.971 & 12 & $.002^{* *}$ \\
\hline & & Eversion & $11.94 \pm 3.90$ & $13.52 \pm 4.22$ & -1.776 & 12 & .101 \\
\hline & \multirow{2}{*}{$\begin{array}{l}\text { Total work } \\
120^{\circ} / \mathrm{sec}\end{array}$} & Inversion & $115.82 \pm 40.31$ & $141.72 \pm 45.94$ & -3.118 & 12 & $.009 * *$ \\
\hline & & Eversion & $71.15 \pm 24.08$ & $75.56 \pm 25.75$ & 0.802 & 12 & .438 \\
\hline
\end{tabular}

\begin{tabular}{|c|c|c|c|c|c|c|}
\hline & & Pre & Post & $\mathbf{t}$ & df & $p$-value \\
\hline \multirow{2}{*}{$\begin{array}{l}\text { Peak torque } \\
60 \% / \mathrm{sec}\end{array}$} & Inversion & $44.86 \pm 26.71$ & $18.52 \pm 27.12$ & 3.942 & 12 & $.002^{* *}$ \\
\hline & Eversion & $17.01 \pm 29.30$ & $4.64 \pm 18.99$ & 2.112 & 12 & .056 \\
\hline \multirow{2}{*}{$\begin{array}{l}\text { Total work } \\
60^{\circ} / \mathrm{sec}\end{array}$} & Inversion & $59.00 \pm 26.80$ & $22.71 \pm 29.08$ & 4.707 & 12 & $.001^{* *}$ \\
\hline & Eversion & $41.10 \pm 26.05$ & $9.78 \pm 20.01$ & 5.686 & 12 & $.000^{* * *}$ \\
\hline \multirow{2}{*}{$\begin{array}{l}\text { Peak torque } \\
120^{\circ} / \mathrm{sec}\end{array}$} & Inversion & $38.03 \pm 32.24$ & $15.68 \pm 24.39$ & 2.977 & 12 & $.012^{*}$ \\
\hline & Eversion & $9.90 \pm 30.70$ & $-8.17 \pm 27.72$ & 2.883 & 12 & $.014^{*}$ \\
\hline \multirow{2}{*}{$\begin{array}{l}\text { Total work } \\
120 \% \text { sec }\end{array}$} & Inversion & $56.97 \pm 31.74$ & $25.08 \pm 28.25$ & 3.962 & 12 & $.002^{* *}$ \\
\hline & Eversion & $36.61 \pm 31.19$ & $2.24 \pm 28.81$ & 6.095 & 12 & $.000^{* * *}$ \\
\hline
\end{tabular}

의 내번 $(\mathrm{p}<.001)$, 외번 $(\mathrm{p}<.01)$, 환측의 total work의 내 번 $(\mathrm{p}<.001)$ 및 외번 $(\mathrm{p}<.01)$ 의 근지구력은 관절경 $\mathrm{MBO}$ 후 재활운동프로그램 적용 전과 비교하여 적용 후에 유 의하게 증가하였다<Table 6>. 또한 건측 peak torque 의 내번 $(\mathrm{p}<.01)$, total work의 내번 $(\mathrm{p}<.01)$ 의 근지구력 도 재활운동프로그램 적용 전과 비교해서 적용 후에 유 의하게 증가하였다.

\section{재활운동프로그램 적용 전·후 근비율 변화}

등속성 근기능의 근력·근지구력의 근비율 $(60 \% \mathrm{sec})$, (120\% $/ \mathrm{sec}$ ) 변화는 <Table 7 >에 제시하였다. $60 \% \mathrm{sec}$ 변화는 peak torque의 내번 $(\mathrm{p}<.01)$, total work의 내 번 $(\mathrm{p}<.01)$ 및 외번 $(\mathrm{p}<.001)$ 의 근력 근비율이 재활운동 프로그램 적용 전보다 적용 후에 유의하게 감소하였다. $120 \%$ sec변화는 peak torque의 내번 및 외번 $(\mathrm{p}<.05)$, total work의 내번 $(\mathrm{p}<.01)$ 과 외번 $(\mathrm{p}<.001)$ 의 근지구력
근비율이 재활운동프로그램 전보다 적용 후에 유의하게 감소하였다<Table $7>$.

\section{논의}

현재 관절경 $\mathrm{MBO}$ 는 발목 염좌 수술의 보편적이고 표준화된 수술 방법으로 많은 환자에게 시행되고 있으 며, 발목 관련 수술 후 빠르고 안정적인 회복을 위하여 수행하 는 재활운동프로그램의 관심도 증가하고 있다. 이러한 추세를 반영 하여 재활운동프로그램의 효과를 증명하는 여러 연구에서 긍정적인 결과가 도출되고 있으나 지금까지 관절 경 $\mathrm{MBO}$ 수술 후 재활운동 프로그램을 적용한 효과를 분석한 연구는 수행되지 않았다.

이에 본 연구에서는 관절경 $\mathrm{MBO}$ 를 시행한 환자를 대상으로 유 연성, 등척성, 등장성, 기능성 및 평형성 향상을 위한 재활운동프로 그램을 적용하여 $\mathrm{AOFAS}$, 발목 관절의 동적 안정성 및 등속성 근기 능에 미치는 영향을 확인하고자 하였다. 
먼저 AOFAS의 선행 연구에서는 60명의 엘리트 선 수가 $\mathrm{MBO}$ 후 재활운동프로그램에 참여한 결과, 참여 자 모두의 발목 관절가동범위, 근력이 향상되어 $\mathrm{AOFAS}$ 평가 항목인 발목 통증, 기능, 정렬의 점수가 높아졌다 [10]. 본 연구에서도 AOFAS의 점수가 유의하게 증가 하여 선행 연구와 일치하였으나 선행 연구에서는 스트 레칭과 달리기만 적용한 결과였으며, 연구 대상자가 선 수라는 제한점이 있었다. 그러나 본 연구의 재활운동프 로그램은 발목 관절가동범위 향상을 위한 유연성 운동, 등장성, 기능성, 평형성 운동을 별도로 구성하였기 때 문에 일반 환자에게 적용하면 더 나은 효과가 있을 것 으로 보인다.

다음으로 동적 안정성의 결과를 비교하기 위하여 $\mathrm{MBO}$ 후 재활운동프로그램을 적용한 선행 연구를 살펴 보았다. 만성 발목 불안정성 발목 기능의 회복을 위해 6 주간 가속재활운동프로그램을 적용한 연구에서는 발목 관절의 동적 안정성이 유의하게 증가하였고[8], 본 연 구에서도 재활운동프로그램을 적용 후 발목 관절의 동 적 안정성이 유의하게 증가하여 선행 연구와 동일한 결 과를 보였다. 선행 연구에서 적용된 수술은 관절경 $\mathrm{MBO}$ 가 아니었으나, 이와 유사한 수술을 시행한 후 재활운 동프로그램을 적용한 사례이기 때문에 같은 연구 결과 로 해석 할 수 있다.

특히 선행 연구에서는 발목의 안정성을 평가하기 위 해 체중 부하를 하였으며, 조기 체중 부하를 포함한 가 속재활운동이 통증을 감소시켜 일상생활과 스포츠활동 으로의 복귀를 앞당길 수 있다고 하였고[8], 본 연구의 재활운동프로그램에서도 발목의 동작 안정성을 증가시 키기 위하여 등척성, 등장성 운동을 구성하였으며, Choi et al.의 선행 연구에서도 동일한 재활운동프로그램운동 으로 동적 안정성을 향상시켰다[8].

발목 염좌의 회복을 강화하기 위해 내번·외번 동작 과 같은 발목 안정성에 기여하는 근육의 향상이 필요하 며, 이를 확인하기 위하여 등속성 근기능(근력, 근지구 력, 근비율)을 측정하였다. 이와 관련한 선행 연구인 재 활운동프로그램이 발목 근육 회복에 미치는 영향을 분 석한 결과는 발목 관절의 내번·외번의 근력과 근지구력 이 증가하였으며 [4], 본 연구의 등속성 근기능(근력, 근 지구력) 측정 결과는 환측과 건측의 내번과 외번 근력 그리고 환측의 내번·외번 근지구력, 건측의 내번 근지 구력이 유의하게 증가하여 일치하는 결과를 나타냈다.
그 이유를 분석하면 발목의 내번 및 외번의 동작에서 가장 크게 사용하는 근육은 비골근과 후경골근(tibialis posterior muscle)이며, 내번과 외번의 직접적인 영향 을 미치는 것은 비골근이다. 내번 동작에서의 비골근의 가장 큰 기능은 발목 관절이 내번 할 때 발목이 과내번 (hyperinversion) 하지 못하도록 조절과 통제하는 것이 나 외번에서의 비골근은 발목의 외번 동작을 만들어내 는 근육이어서[3] 비골근의 강화로 환측의 근력과 근지 구력이 증가하였다고 볼 수 있다.

등속성 근기능 중 근비율의 분석결과, 환측과 건측 의 근력 근비율은 외번 peak torque를 제외하고 유의 하게 감소하였으며, 근지구력 근비율도 유의하게 감소 하였다. 이는 Shin et al.의 6주간 운동재활프로그램을 적용한 연구에서 나타난 환측의 내·외번 근력이 증가하 고, 근비율이 개선되었다[2]. Choi et al.의 연구에서도 $\mathrm{MBO}$ 후 조기재활운동프로그램을 6주간 시행한 연구 에서도 근력과 근지구력이 향상되어 환측과 건측의 근 비율이 감소되어 본 연구의 결과와 동일하였다[8]. 근 비율은 근결손율을 의미하기에 근결손이 감소하였다는 것은 곧 재활운동프로그램의 효과를 보여주는 것이다.

본 재활운동프로그램에서는 발목 회복에 주된 역할 을 하는 근기능을 향상시키기 위해 등장성, 기능성, 평 형성 운동을 집중적으로 구성하였는데, 이는 발목 주변 근육의 근력 강화 운동이 발목 불안정성을 회복하는데 중요한 역할을 한다고 보고한 Choi et al.의 의견과 일 치한다[8]. Shin et al.의 재활운동프로그램에서는 등장 성 운동과 평형성 운동을 제시하였고[2], Choi et al.의 연구에서는 등장성 운동 외 별도의 다양한 개인 운동을 구성하여 근력을 강화하였다[8].

이렇듯 $\mathrm{AOFAS}$, 동적 안정성, 등속성 근기능의 근 력, 근지구력, 근비율의 분석 결과는 선행 연구와 일치하 는 부분이 많았으나, 등속성 근기능의 근력과 근지구력 의 일부분은 선행 연구와 일치하지 않았다. 그 예로 Cha et al.의 연구에서는 발목 재활 훈련으로 원판 운동과 트 램폴린 운동을 적용한 결과 두 그룹 모두 좌측과 우측의 내번과 외번 근력이 유의하게 증가하였다[5]. 그러나 본 연구에서는 건측의 외번 일부인 $60 \%$ sec total work의 근력과 근지구력이 모두 유의하게 증가하지 않았다. 이 러한 이유는 수술 후 초기에는 환측의 유연성 확보와 근 력 향상을 시키기 위해 환측 부위의 운동을 주로 하였 고, 그 후 기능적인 운동을 환측과 건측에 같이 적용하 
였기 때문에 상대적으로 건측에 적용된 운동량이 적은 것으로 판단된다. 이러한 결과를 참고하여 추후, 건측의 부분 운동도 수술 후 초기부터 시행하거나 건측 부분의 운동량을 늘리는 것을 고려할 수 있다.

전술한 바와 같이, 본 연구의 재활운동프로그램이 관 절경 $\mathrm{MBO}$ 후 적용되었을 때 적절한 효과가 있다고 판 단되어 추후 관절경 $\mathrm{MBO}$ 수술 후 재활운동프로그램 도 입의 가능성을 확인하였다. 또한 본 연구는 최근 표준 화된 수술인 관절경 $\mathrm{MBO}$ 후 재활운동프로그램의 최초 의 적용 사례이기 때문에 재활운동프로그램의 구성은 전문가가 제시한 내용을 변형하여 사용하였다. 그러므 로 본 연구의 재활운동프로그램에 관하여 운동전문가, 물리치료사, 의료진의 의견을 수렴하고, 이를 바탕으로 프로그램을 재구성하는 가능성도 열려있다고 생각한다.

\section{결론 및 제언}

본 연구는 관절경 $\mathrm{MBO}$ 후 13 명의 환자를 대상으로 유연성, 등척성, 등장성, 기능성 및 평형성 향상을 위한 6 주간의 재활운동프로그램을 수행한 결과, $\mathrm{AOFAS}$, 동 적 안정성 및 등속성 근기능이 향상되는 것으로 나타났 다. 따라서 관절경 $\mathrm{MBO}$ 후 환자의 재활운동프로그램 구성에 필요한 기초 연구 자료로서의 활용이 가능하다 고 생각된다.

본 연구의 제한점으로 첫째, 연구의 참여자가 $\mathrm{D}$ 병원 의 수술 후 재활운동프로그램의 대상자로 한정되었다. 둘째, 본 연구는 기초 연구로서 참여자가 13 명이기에 양 적으로 충분하지 않아 연구 측정 결과의 일반화가 어려 울 수 있다. 셋째, 본 연구는 재활운동프로그램에 참여 하지 않는 대조군이 없이 연구되어 재활운동프로그램 의 완전한 효과성을 판단하기에 한계가 있었다. 넷째, 본 연구에서는 재활운동프로그램 적용을 6 주로만 하였 기에 장기적 기간의 적용 결과를 추론할 수 없었다. 이 때문에 본 연구의 결과를 기초 연구 자료로 하여 추후 연구에서는 재활운동프로그램에 참여하지 않은 대조군 포함 및 연구 대상자의 충분한 인원을 확보하고, 6 주 이 상의 장기적 기간을 적용하는 등의 구체적인 연구를 수 행할 필요성이 있다.

\section{Conflicts of Interest}

The authors declare no conflict of interest.

\section{References}

1. Shin SI, Kim GL, Jo JS, Lee HB, Kwon JW. Modified Brostrom Procedure with Suture Anchor \& PushLock Anchor in Lateral Ankle Instability. Korean Foot Ankle Soc. 2012; 16(4): 241-6.

2. Shin JH, Jang JH. Changes of muscular function after 6-week-exercise rehabilitation program application for female MBO patients with associated injury. J Exerc Rehabil. 2010; 6(4):127-37.

3. Karlsson J, Eriksson BI, Bergsten T, Rudholm O, Swärd L. Comparison of two anatomic reconstructions for chronic lateral instability of the ankle joint. Am J Sports Med. 1997; 25(1): 48-53.

4. Rhi SY, Chung JS, Kim YS. The Effects of Early Rehabilitation Exercise after Modified Brostrom Operation on Ankle Muscle Recovery in Chronic Ankle Instability Patients. Korean Soc Growth Dev. 2011; 19(1):43-8.

5. Cha SH, Kim WW, Leem MY. Effects of training mode on range of motion and isokinetic muscle function during ankle rehabilitation. Asian J Kinesiol. 2009; 11(1):43-52.

6 . Hertel J. Functional instability following lateral ankle sprain. Sports med. 2000; 29(5):361-71.

7. Cha MS, Cha SD, Kim ES. Surgical Outcomes of Arthroscopic Modified Brostrom Procedure in Chronic Lateral Ankle Instability. Korean Foot Ankle Soc. 2013; 17(4):283-7.

8. Choi IH, Lee JK. Effect of Accelerated Rehabilitation with Anti-Gravity Treadmill Exercise on Ankle Joint Function After Surgery of Modified Brostrom Operation in Chronic Ankle Instability Patients. J Korea Academia-Ind cooperation Soc. 2019; 20(7):228-35.

9. Mangwani J, Hakmi M, Smith T. Chronic lateral ankle instability: review of anatomy, biomechanics, pathology, diagnosis and treatment. The foot. 2001; 11(2):76-84.

10. Lee K, Jegal H, Chung H, Park Y. Return to play after modified Broström operation for chronic ankle instability in elite athletes. Clin Orthop Surg. 2019; 11(1):126.

11. Brotzman S, Wilk E. Clinical orthopaedic rehabilitation(2nd Ed.). Mosby Philadelphia. 2003, p 
391-392.

12. Button G, Pinney S. A meta-analysis of outcome rating scales in foot and ankle surgery: is there a valid, reliable, and responsive system? Foot Ankle Int. 2004; 25(8):5215.
13. Plisky PJ, Grman PP, Butler RJ, Kiesel KB, Underwood FB, Elkins B. The reliability of an instrumented device for measuring components of the star excursion balance test. N Am J Sports Phys Ther: NAJSPT. 2009; 4(2):92. 